\title{
A NOÇÃO DE GOVERNANÇA: UMA MESOCATEGORIA DA AÇÃO COLETIVA
}

\section{The notion of governance: a mesocategory of collective actions}

Anete B.L. Ivo (UFBA/UCSAL)

Lattes Id http://lattes.cnpq.br/963891790286336o

\author{
Informações do artigo
}

Recebido em 08/03/2020

Aceito em 10/04/2020

doi>: https://doi.org/10.25247/2447-861X.2020.n249.p63-82

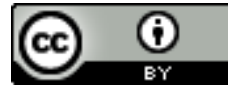

Esta obra está licenciada com uma Licença Creative Commons Atribuição 4.0 Internacional.

\section{Como ser citado (modelo ABNT)}

IVO, Anete B.L. A noção de governança: uma mesocategoria da ação coletiva. Cadernos do CEAS:

Revista Crítica de Humanidades. Salvador, v. $45, \mathrm{n}$.

249, p. 63-82, jan./abr. 2020. DOI: https://doi.org/10.25247/2447-861X.2020.n249.p63-82

\begin{abstract}
Resumo
Este artigo examina as origens e os limites da noção de governança, como uma mesocategoria da ação coletiva de caráter polissêmico, observando contextos políticos distintos, ou seja, do neoliberalismo às tendências contra-hegemônicas de lutas e demandas da cidadania nos territórios. O esforço analítico relaciona a noção de governança com as práticas, discursivas e conceituais, politicamente 'situadas', que estabelecem relações dialéticas entre conhecimento e política, sob a forma de conflitos cognitivos sobre a regulação social nos territórios e os direitos de grupos sociais em disputa. Trata-se de observar os arranjos de governança quanto às relações de poder, cuja dinâmica não se restringe exclusivamente ao Estado, mas envolve forças sociais em conflito, mediadas por processos cognitivos e simbólicos de construção da hegemonia na política.
\end{abstract}

Palavras-chave: Governança. Mesocategorias Sociais. Ação Coletiva. Teoria Social. Neoliberalismo.

\section{Abstract}

This article examines the origins and limits of the notion of governance, as a mesocategory of the - polysemic natured - collective action, observing different political contexts, namely, from neoliberalism to the counterhegemonic tendencies of struggles and demands of citizenship in territories. The analytical effort links the notion of governance with the practices, discursive and conceptual, politically 'situated', which establish dialectical relations between knowledge and politics, in the form of cognitive conflicts over both the social regulation in the territories and the rights of social groups in dispute. It is about observing the governance arrangements with regard to power relations, whose dynamics are not restricted exclusively to the State, but involve social forces in conflict, mediated by cognitive and symbolic processes of construction of hegemony in politics.

Keywords: Governance. Social Mesocategories. Collective Action. Social Theory. Neoliberalism. 


\section{Introdução}

A noção de governança constitui-se uma mesocategoria da ação coletiva que aparece ao final da década de oitenta, em documentos do Banco Mundial, como alternativa ao desenvolvimento local. Essa noção foi sendo gradativamente apropriada pelo senso prático como uma categoria da ação dos agentes sociais em contextos de luta e resistência nos territórios, gerando polissemia conceitual, no âmbito sociológico.

A análise recompõe a constituição dessa categoria de alcance médio atrelada originalmente à agenda liberal global, e como a apropriação dessa noção da ação pública, no curso da práxis dos agentes, assimila novos regimes de conhecimento dos atores no contexto contemporâneo. O esforço analítico articula a formação da noção com as estruturas sociais, políticas e institucionais em práticas discursivas e conceituais 'situadas', estabelecendo relações dialéticas entre conhecimento e política, expressas na forma de conflitos cognitivos sobre a regulação social dos territórios e grupos sociais. Trata-se, pois, de observar a realidade intrínseca à relação de poder, cujo objetivo não se restringe ao funcionamento da ação do Estado, mas envolve a mediação de forças sociais em conflito. A ideia é trazer elementos que demonstrem novos modos de subjetivação dos agentes sociais nas relações de governo, estruturados por normas.

\section{Suportes teóricos para uma categoria do senso prático}

A palavra governança apoia-se na noção foucaultiana de "governamentalização" (gouvernamentalité) (FOUCAULT, 1979) das relações de poder sob a caução dos Estados nacionais, e, acrescento, também, das instituições multilaterais de desenvolvimento, no contexto da globalização. Essa racionalidade opera no campo das instituições e nas análises científicas, na forma de relações de poder que integram a construção de um Estado gerencial sobre a população, entendida como governo.

Essa "governamentalização" implica concertação de interesses divergentes entre agentes do mercado, Estado e sociedade, e mobiliza uma inteligência voltada para produzir consensos (mesmo parciais) e inovações aos processos reais. Os arranjos de governança são partes, portanto, de um processo contínuo de racionalização, controle e dominação da vida social das populações, em contextos assimétricos de conflito. Esse regime de ação coletiva não se confunde com a ação de governos, mas busca abarcar o poder dos atores sociais e 
civis, sob o paradigma de regimes de "cooperação", pactuação e consensos parciais, mesmo em contextos de conflitos sobre bens, políticas e territórios.

Esse regime de ação mobiliza conhecimentos sociológicos e antropológicos na produção da política, atribuindo novos sentidos às ações dos agentes em projetos de desenvolvimento em escala local convergentes com a realidade desses sujeitos socioculturais em conflitos territoriais e direitos. As ciências sociais constituem-se, portanto, em mediadoras das relações de poder, pelo confronto de saberes diferenciais em disputa, que podem resultar em formas sutis de subalternidade da cidadania ou neutralização do poder social desses agentes, mas, também, podem fazer emergir, alternativamente, projetos contra-hegemônicos, a depender da força e organização desses agentes sociais em luta.

Portanto, a inter-relação entre a sociedade, a economia e os governos confronta conhecimentos que podem resultar na recriação da economia (para além do mercado); das instituições (para além dos governos) e dos territórios (para além da natureza), traduzida em relações sociologizadas e politizadas, em processos de lutas entre atores sociais, na defesa de bens naturais e públicos, em contextos assimetrias de poder, que envolvem hierarquias e dominação.

A noção de governança como mesocategoria da ação prática de caráter polissêmico transita desde o contexto dos ajustes neoliberais e reformas de Estado, dos anos noventa, e abarca gradativamente a contra tendência dos agentes socioculturais em movimentos de resistências e defesa de territórios diante da intervenção pública e privada de grandes projetos, constituindo-se, portanto, em uma noção contingente da ação prática e estratégica dos agentes em disputa por políticas e territórios.

\section{Origem e sentidos dessa noção de governança no contexto neoliberal}

A noção de governança aparece originalmente em relatórios do Banco Mundial como alternativa à crise do crescimento dos anos oitenta, como uma resposta estratégica possível a essa crise. Em uma reunião acadêmica realizada na África, em $1989,{ }^{1}$ alguns pesquisadores buscaram discutir, delimitar e questionar a noção de governança (MCCARNEY; HALFANI;

\footnotetext{
1 Reunião do Programa de Governança na África (Universidade Emory), em 1989, em que Richard Joseph
} debateu sobre a noção com 30 acadêmicos. (Informação em: MCCARNEY; HALFANI E RODRIGUEZ, 1998). 
RODRIGUEZ,1998): (i) segundo Lofchie (1989), ela significa um "poder real", sem locus para o seu exercício efetivo, que reconhece a importância crescente das redes sociais e do capital social, bem como as formas de mediação entre Estado e Sociedade Civil; (ii) Mick Moore (1993) a distingue da noção de "bom governo" e aproxima-a mais da ideia de 'capacidade efetiva de poder da sociedade', que pode estar tanto no governo, como em outros segmentos da sociedade e do estado, como ONGs, movimentos sociais, setores da justiça etc. Para ele, as qualidades desse poder é que assumem caráter normativo; (iii) para Hyden; Bratton (1992, p. 7), o uso da noção refere-se ao manejo de estruturas mediadoras em espaços de concertação com vistas à legitimidade, referindo-se à integração entre sociedade e Estado. O resultado desse debate, portanto, entende a governança como um processo de capacitação de um poder real, sendo, portanto, mais ampla que a noção de governo.

O relatório do Banco Mundial a Sub-Saharan Africa. From crisis to sustainable growth (WORLD BANK,1989) localiza a crise de crescimento da África como "crise de governo" e destaca a busca de "legitimidade política e o consenso como condições para o desenvolvimento sustentável". Segundo David William e Tom Young (1994, p. 84-85), o Diretor do Centro Carter de Governança Africana identifica o processo de accountability "prestação de contas" como o elemento mais importante do processo de governança no contexto das reformas neoliberais, o qual só pode ser alcançado por meio de eleições competitivas. Outros autores entendem que a melhoria de desempenho dos governos supõe regimes democráticos associados a atributos morais de desempenho dos agentes, a exemplo das normativas de um governo responsável e confiável com respeito aos direitos humanos, e que envolvam a participação popular nos processos políticos.

Em 1992 o Banco Mundial produziu um novo relatório - Governance and Development -, (WORLD BANK, 1992) que estabeleceu nexos mais diretos entre governança e desenvolvimento. Neste documento, a noção "governança" foi definida como "a maneira pela qual o poder é exercido na gestão de recursos econômicos e sociais para o desenvolvimento de um país". O documento desdobra-se num conjunto de regras e instituições que orientam as relações complexas entre a vida privada e as instituições públicas, associando a essas um conjunto "qualidades morais" de "bom governo" para o controle da ação pública: capacidade de previsibilidade; formulação de políticas abertas e claras (isto é, adoção de processos transparentes); burocracias imbuídas de ética profissional; um executivo responsável por suas ações; uma sociedade civil com forte 
interesse e participação em assuntos públicos; sendo que todas essas recomendações são orientadas e ajustadas a 'comportarem-se' segundo "as regras" do Estado de direito. Ou seja, essas recomendações implicam, portanto, formas de disciplinamento de condutas dos agentes. Mas o Banco Mundial é uma instituição financeira e se preocupa com a sustentabilidade da ajuda financeira do Banco aos países.

Interpretando as normativas sugeridas pelo Banco, a noção visa produzir, na sua origem, uma adaptação das instituições e ações dos governos à liberalização dos mercados, atuando, originalmente, em escala macroeconômica e política. Para tanto, evolui de acordos globais estabelecidos entre Estados, passando pelo saneamento dos Estados nacionais, e desdobra-se, no âmbito municipal ou local, na adoção de mecanismos de democratização participativos, controle social e transparência; ou, ainda, recomendando formas de integração dos pequenos agentes econômicos ao mercado em escala microssocial via programas de inserção produtiva, economia solidária, micro crédito, empreendedorismo etc.

Na forma de uma categoria intermediária da ação pública, o termo governança abarca uma ação estratégica entre atores públicos e privados, que se efetiva em diferentes níveis de escalas e contextos específicos de ação. Em escala transnacional mobiliza a comunidade internacional e os sistemas de governança global na regulação de formas de cooperação entre países e grandes corporações empresariais com os Estados. No âmbito dos Estados nacionais atua na devolução de poder para os lados (privatizações e parcerias) ou verticais (entre o Estado nacional e os entes subnacionais) em processos de descentralização e desconcentração da instância de governo nacional. Na instância local - a local governance incorpora formas participativas e arenas de concertação entre atores da sociedade civil, do mercado e do Estado, na intervenção e implementação de programas locais de grande impacto territorial ou populacional (infraestrutura ou desenvolvimento territorial) que afetam as condições de vida e trabalho dos moradores e o direito dos cidadãos sobre a cidade ou territórios.

Os sistemas de governança local, no plano normativo, caracterizam-se por arranjos horizontais, na forma de regimes de cooperação entre agentes públicos e privados, visando à produção de consensos na implementação de programas de desenvolvimento local ou políticas públicas. O paradigma da "cooperação" sugere, antecipadamente, um suposto virtuosismo de ações solidárias entre agentes, e tem função simbólica que funciona na neutralização do conflito preexistente (explícito ou não-explícitos) e na pacificação das 
relações assimétricas e contraditórias entre mercado, agentes públicos e o poder social nos territórios. Esses arranjos seguem regras da democracia liberal, mas estão constrangidos pelo poder de poderosas corporações econômicas e agentes públicos, que buscam legitimar as suas ações na formação de consensos mínimos (IVO, 1997). O resultado dessas arenas de disputa pode reforçar mecanismos de dominação e disciplinamento das populações nos territórios, mas é possível gerar alternativas favoráveis aos atores em luta por direitos nesses territórios.

\section{Crítica à perspectiva neoliberal da governança local: um Estado para o mercado}

Observando os dispositivos neoliberais da "boa governança", definidos nos diagnóstico do Banco Mundial (WORLD BANK,1989), observa-se uma conversão das relações políticas, ou das relações de poder na forma de procedimentos técnicos e avaliação de desempenho institucional dos governos (enxugamento da máquina do Estado; controle fiscal; controles de qualidade; gestão dos gastos etc.) às quais se associam regras contratuais e códigos de conduta em acordos mínimos parciais e pequenos pactos antecipados (consensos mínimos, IVO, 1997), que contribuem, ao mesmo tempo, no disciplinamento dos agentes e na formação de consensos parciais e relativos.

Da perspectiva da agenda neoliberal, a noção de governança baseia-se no campo doutrinário dos valores liberais (pluralismo, sociedade civil, responsabilidades, emancipação e empreendedorismo), deslocando-se para um campo estratégico da ação prática, definida por regras de "como atuar", controlando a conduta dos agentes sociais e dos governos, nos países.

Por meio de uma reengenharia das estruturas institucionais dos governos nacionais, mobilizam-se valores doutrinários do Estado liberal, considerados pressupostos virtuosos e "eficientes", que são traduzidos em regras disciplinadoras da gestão (em termos de capacidade técnica e responsabilidades) e convenções, as quais, na prática, reorientam politicamente os governos, os agentes públicos e as populações. O Banco articula, às técnicas institucionais de gestão, também "normas morais" que influenciam o disciplinamento das condutas dos agentes públicos e sociais, na formação de um Estado gerencial reformado, em favor dos mercados. 
Essas orientações estratégicas do Banco visam adaptar os governos nacionais à liberalização da economia global, garantindo saneamento dos Estados nacionais, e respostas às demandas sociais pela co-responsabilidade na resolução das demandas sociais. Rhodes (1996) associa seis usos da noção de governança vinculados à agenda de liberalização das economias, na literatura internacional: a tese do Estado mínimo; a governança corporativa; a nova gestão pública; o "bom governo"; os sistemas sociocibernéticos e redes autoorganizativas. Confirmando essa tese de funcionalidade dos governos à liberação da economia, o Presidente do Banco Mundial, ${ }^{2}$ declarou, em discurso em 29.08.1991, que a gestão pública deve acompanhar a liberalização da economia como condição de desenvolvimento econômico; e que a estabilidade política e a gestão econômica e fiscal constituem-se pré-requisitos do desenvolvimento. Ao disciplinar a conduta dos agentes econômicos, o Banco Mundial acaba por interferir sutilmente no governo dos países, por via de recomendações, avaliações sistemáticas e programas de capacitação técnica de programas públicos financiados, sob a justificativa de medidas de "eficiência dos serviços públicos".

No relatório do Banco Mundial - The State in a Changing World - de 1997 (WORLD BANK,1997), o Estado nacional ganha centralidade como ator relevante das transformações contemporâneas, pelo revigoramento das instituições públicas. Mas o Relatório propõe, ao mesmo tempo e claramente, uma externalização e devolução de funções públicas para o mercado, e o exercício de responsabilidades partilhadas com agentes privados, no provimento das políticas sociais e serviços públicos e urbanos. Essa inflexão implica reforço à provisão privada de serviços, como registra o Banco, com base em adjetivações e qualificações antecipadas das instituições existentes nos países como "fracos" ou "fortes".

[...] Países com instituições públicas fracas devem dar total prioridade à busca de caminhos para a utilização de mercados e para envolver empresas e outros provedores não governamentais na provisão de serviços (WORLD BANK, 1997, p. 60).

O "fortalecimento" institucional do Estado, nesse documento, baseia-se numa ideia de "flexibilização" das relações entre Estado e sociedade. Ademais, o relatório alude a

\footnotetext{
2 Presidente Conable no prefácio do texto Managing development: the governance dimension. Posteriormente integrado no documento World Bank, 1992. (OSMOND, 1998, p. 19)
} 
problemas inerentes à cultura política nos países, como a corrupção sistêmica e a insegurança jurídica, como fatores que afetam especialmente os países em desenvolvimento, e que, portanto, necessitam ser saneados. Nessa linha, reconhece a ambiguidade de governos formalmente democráticos, mas que procedem de forma autoritária, destaca o caráter "predatório" e patrimonialista de muitos Estados considerados "modernos" - a exemplo dos tigres asiáticos descritos como retardatários - late comers- (p. ex., Indonésia, Filipinas e até a poderosa Coréia do Sul). E alerta, ainda, quanto ao "perigo" de grupos de interesse locais, que podem influenciar na formulação de políticas.

[...] nem todas as organizações da sociedade civil são adequadamente representativas, seja de seus membros, seja do público em geral [...] os governos devem ter consciência dos interesses que esses grupos defendem, assim como dos interesses que eles não representam. (WORLD BANK, 1997, p. 113)

Anick Osmond (1998), ao analisar os dispositivos de governança propagados pelo Banco, conclui que eles servem, em realidade, para ele exercer o "controle de políticas de reforma dos países, sem ser acusado de ingerência política" ${ }^{3}$. Ademais, acrescento, na área social, a orientação da economia converte políticas sociais redistributivas, assentadas na Seguridade Social e com base na dinâmica dos mercados de trabalho, numa agenda internacional de luta contra a pobreza.

Essa agenda pró- pobres, como analiso em livros anteriores (IVO, 2004 e 2008), desloca a pobreza e a distribuição de renda dos seus determinantes estruturais, passando a entendê-la como estado de carências dos "indivíduos" e não como resultado de um modelo desigual de rendas e dificuldades de acesso ao trabalho e aos bens públicos ${ }^{4}$, próprios à dinâmica da produção do valor em regimes de acumulação globalizado.

Muitos autores (WILLIAM; YOUNG, 1994; MCCARNEY; HALFANI; RODRIGUEZ, 1998; OSMOND, 1998; LAUTIER, 2010; E IVO, 2001 e 2016) questionam a neutralidade

3 Os cinco países que mais contribuem financeiramente no BIRD são: EUA (16,53\%); Japão (7,93\%); Alemanha $(4,53 \%)$ Reino Unido $(4,34 \%)$ e França $(4,34 \%)$. Essa participação indica forte hegemonia dos EUA e do Japão nas decisões. Alemanha, França e Reino Unido alcançam, juntos, 13,09\% e não chegam ao percentual de participação dos EUA. (CAVALCANTI, 2008, p. 53).

4 No livro Metamorfoses da questão democrática: governabilidade e pobreza (IVO, 2001), analiso as diversas noções de pobreza e a focalização da assistência no contexto neoliberal e observo os limites desses processos em relação à estrutura urbana e a democracia das cidades, concluindo por mostrar como a apropriação da cidade pelo mercado acaba reforçando a segregação social das cidades e reforçando um aggiornamento da direita. 
política das orientações prestadas pelo Banco Mundial, vez que essas são partes de políticas interessadas do setor financeiro, que confrontam os pilares do Welfare. A estratégia de separação entre o que é "técnico" e "político" sempre se constituiu em um artifício para despolitizar as questões políticas, considerando-as supostamente neutras. Exaltando fundamentos do liberalismo político, o Banco declara que o Estado deve ser 'neutro' em relação ao que considera como o "bem central", qual seja, para o Banco, o controle e a defesa da propriedade privada. Portanto, fundado em princípios de pluralismo liberal e em suposta neutralidade técnica, o Banco atua no reforço às normas e parâmetros de conduta, no disciplinamento dos sujeitos, das instituições reorientando o sentido da política.

\section{A ação de governança e subjetividade dos agentes no contexto neoliberal}

Três estratégias articuladas dos dispositivos de governança produzem efeitos simbólicos e influenciam a subjetividade dos agentes sociais e políticos na formação do consentimento. A primeira estratégia refere-se à disseminação de dispositivos normativos morais do "dever ser" para a esfera pública, que subordina os sujeitos às sanções prévias pactuadas em códigos de conduta dos agentes e disciplina-os na participação de programas públicos de diferentes nuanças: a responsabilidade fiscal; a luta contra a corrupção; a cooperação público-privada; o pluralismo; a luta contra a pobreza; a justiça por equidade etc. A segunda transforma políticas públicas de Estado em "técnicas" de gestão, expressas em regras e normas de condutas, controles financeiros, eficiência de alocação de recursos, transparência e controles sociais, avaliações de desempenho, treinamentos e capacitação etc. ${ }^{5} \mathrm{~A}$ terceira, menos explícita diretamente, neutraliza os princípios da justiça redistributiva próprios do Estado de bem-estar, substituindo garantias e direitos sociais constitucionais por programas focalizados de luta contra a pobreza, dissociados do mercado de trabalho. Exemplo dessas ações encontra-se na ativação dos trabalhadores como empreendedores,

\footnotetext{
5 Lautier (2010) analisa como os programas de avaliação e de capacitação dos agentes atuam na disseminação de normas e valores liberais que são gradativamente internalizados pelos sujeitos, facilitando a produção de consensos e, acrescento, produzindo uma fidelização desses sujeitos à ação dos governos. Esse processo consolida uma "comunidade epistêmica" (HAAS, 1992) em favor da agenda da transição liberal (IVO, 2015). Essa se compõe de uma rede de profissionais, em todo o mundo, que promove a transferência de conhecimentos e uma socialização de agentes públicos com esses novos valores das agências internacionais. Eles compartilham "crenças" que fornecem os fundamentos morais, técnicos e políticos, "num movimento amplo de construção do consentimento, como forma de hegemonia".
} 
ou, ainda, na ênfase legítima da luta contra as desigualdades socioculturais, baseada na matriz do reconhecimento (de direitos civis e políticos), separadas das políticas redistributivas de renda, como (direitos sociais). O conjunto desses dispositivos simbólicos e táticos acabam pacificando as relações políticas entre agentes.

William; Young (1994) destacam dois aspectos críticos, implícitos à noção de governança para o desenvolvimento, nos documentos do Banco. O primeiro se refere à criação de estruturas legais das "áreas técnicas" para o desenvolvimento institucional e a "capacitação" dos agentes. Essa área é definida por regras instrumentais de um sistema de direito contratual, firmadas como fundamentos da "justiça" e "liberdade" (p. 86-87), entendidas como processos de governança. O segundo, como apresentado no relatório Governance and Development (WORLD BANK, 1992, p. 49), implica uma percepção ampla e instrumental da sociedade civil (desde as organizações voluntárias, passando pelas organizações não-governamentais, e incorporando atores relevantes da sociedade civil, como universidades, sindicatos e organizações profissionais) na busca por legitimidade.

A noção de sociedade civil é central aos dispositivos participativos e de controle social difundidos pelo Banco. Como instituição financeira, o Banco evita tratar de questões democráticas e, ao invés da defesa de um regime democrático, afirma indiretamente valores da democracia liberal como virtudes implícitas aos atores da "sociedade civil" (participação, responsabilização, legitimidade etc.) na construção do que, mais tarde, ele irá chamar de esfera pública liberal.

A noção de sociedade civil, no entanto, é bastante complexa ${ }^{6}$ e não se restringe ao uso instrumental de responsabilidades compartilhadas ou de atores capacitados para a formulação, controle e execução de políticas públicas, como explicitados nas normativas do Banco. Essa formulação ampla e institucional da sociedade civil parece reduzi-la a uma "esfera autônoma, sem conflitos, destituída da prática política no sentido amplo"

\footnotetext{
${ }^{6}$ A noção de sociedade civil (SC) em Gramsci (1999) significa "hegemonia política e cultural de um grupo social sobre toda a sociedade, como conteúdo ético do Estado" (SIMIONATO, 2010, p. 50). Associada às recomendações das ações de governança, a noção de sociedade civil assume um conteúdo normativo virtuoso e produtora natural de efeitos democratizantes nos planos político, cultural e econômico. Do ponto de vista do governo (IPEA, 2010, p. 50) a sociedade civil compreende o conjunto de atores habilitados a assumir funções institucionalmente reconhecidas no desenho, controle e execução de políticas públicas, bem como na representação de públicos diversos e interesses difusos.
} 
(SIMIONATO, 2010, p. 48), na qual não haveria possibilidade de construção de um projeto político sob hegemonia das classes subalternas.

Assim, por meio da disseminação de normas políticas, culturais e sociais, realizadas por instituições "privadas" da sociedade civil, as agências multilaterais e os governos organizam ativamente o consenso e "governam" relações de poder.

\section{As escalas dos processos de governança para o desenvolvimento}

A ação de governança difundida pelo Banco se efetiva em diferentes escalas, do nível macro ao micro. No âmbito macroestrutural, o Banco orienta a criação de sistemas eficazes de prestação de contas no desempenho econômico e na responsabilização financeira. Em termos microssociais, incentiva a mobilização dos agentes, permitindo que a "voz" dos pobres seja ouvida, além de criar 'oportunidades' e «saídas» alternativas aos problemas sociais, mediante o protagonismo desses próprios agentes.

McCarney; Halfani; Rodriguez (1998) reconhecem a potencialidade da noção de governança para regimes de desenvolvimento por ela ultrapassar o economicismo dos ajustes estruturais restritos à "eficiência" de governos e incorporar a dimensão da política nos diálogos sobre desenvolvimento, ajudando a superar uma percepção cêntrica do Estado sobre a sociedade. Para esses autores, a noção de governança contém uma crítica ao estruturalismo das análises econômicas do desenvolvimento, na medida em que incorpora processos democráticos de valorização do poder civil em novos pactos sociais e republicanos.

Os agentes da reforma neoliberal também realizaram uma autocrítica ao economicismo monetarista, no início do século $\mathrm{XXI}$, reconhecendo que a ortodoxia econômica liberal acabou agravando o empobrecimento das classes populares 7 , e rompendo os nexos críticos entre desenvolvimento e pobreza. Essa crítica ao caráter restrito das abordagens economicistas sobre o desenvolvimento sugere avançar-se em novas concepções de política, que coloquem o poder social a serviço dos governos. Essa orientação permitiria maior eficácia do processo decisório, para além dos governos e baseada em

7 Designo classes populares como um amplo segmento de pessoas e famílias que se reproduzem e trabalham em condições de pobreza. A noção abarca tanto empregados assalariados como os trabalhadores autônomos e por conta própria, cujos níveis de rendimentos situam-se nos estratos mais baixos da pirâmide de renda. 
centros de poder real, podendo estes estar na sociedade, nos movimentos identitários de minorias, nas ONGs, ou na articulação entre essas e os governos.

\section{A dialética entre governo e sociedade: a reversão dos arranjos de governança pela cidadania}

A dinâmica das lutas e o processo de diferenciação política dos agentes sociais levaram a uma crítica ao economicismo da noção do desenvolvimento dos anos 1960-1970. No curso da formação de movimentos identitários, novos atores emergem e influenciam a implementação das políticas de desenvolvimento local e sustentáveis, apoiados no reconhecimento da participação social e cidadã e na defesa do Direito aos bens naturais e aos bens públicos comuns (tanto na agenda urbana do Direito à cidade, como na luta em defesa dos povos nos territórios).

A reversão dos arranjos de governança em espaços da cidadania

No curso dessas lutas e da ação pública, a noção de governança foi sendo gradativamente apropriada por diferentes atores sociais e políticos em confrontos e lutas "situadas" na negociação de suas demandas e direitos. Essa apropriação dos espaços de concertação pelos atores sociais organizados na defesa de seus direitos reflete, em realidade, uma integração assimétrica das diferentes forças sociais na esfera pública: aquelas que alimentam uma cumplicidade com os dispositivos do ajuste do Estado e em favor da liberalização do mercado; e as que buscam recriar, no âmbito das sociedades locais, projetos inovadores e democráticos da cidadania, na construção de um desenvolvimento local e sustentável da perspectiva do direito dos povos e cidadãos aos seus territórios.

A dialética das lutas sociais deixa, portanto, um campo aberto à ação política. Os atores sociais e políticos, organizados em arranjos de governança, apropriam-se dos dispositivos criados para a ação pública na intermediação das demandas em arenas concertadas entre agentes do Estado, empresas e da cidadania em geral, para criarem alternativas de desenvolvimento local. Ocorre, portanto, uma reapropriação dos espaços de governança pela força da cidadania organizada, enfatizando alternativas e capacidades inovadoras, na tomada de decisões para o desenvolvimento territorial e local, sustentada pelo protagonismo desses agentes socioculturais e econômicos e os direitos da cidadania. 
Para a comunidade dedicada ao problema do desenvolvimento sustentável a importância dessa noção está na incorporação desses agentes sociais em interface com as instâncias oficiais de governo, em Fóruns e Conselhos, no reconhecimento do poder (social), na tomada de decisões, na garantia da cidadania em relação ao direito à cidade e os direitos de povos originais ou comunidades tradicionais aos seus territórios e à sua cultura.

Três noções de governança na produção sociológica contemporânea

Considerando a literatura internacional sobre governança, a noção abarca três dimensões que correspondem a contextos e ao protagonismo distinto de agentes: a) governança como governo- ênfase dos ajustes neoliberais e dispositivos de reforma em favor do mercado; b) as arenas mediadoras (fóruns, conselhos etc.) de processamento das relações conflitivas entre diversos atores nos territórios (nas cidade e no meio rural); e c) arranjos nos quais prevalecem processos de socialização da vida e do trabalho promovidos pelas classes populares, na vivência cotidiana das instituições públicas e privadas, visando a sua reprodução social, fundada numa "política do cotidiano" desses agentes. A política, aqui, ultrapassa a dimensão da ação governamental e remete à vivência da cidadania, que organiza a sociabilidade desses sujeitos, no campo e na cidade.

\section{A - Governança e participação no contexto dos ajustes liberais ${ }^{8}$}

Essa noção da governança visa a uma adequação instrumental dos Estados nacionais ao mercado, no contexto de vigência neoliberal e da globalização (Fundo Monetário Internacional - FMI). Lança mão da potencialidade cívica e social, estimulando um liberalismo social de tipo assistencial e de ativação da força de trabalho, fora do modelo de Estado de BemEstar social. Opera nos limites da tese da governabilidade pelo controle fiscal, sem os riscos de 'muita democracia', ou da politização das relações assimétricas do trabalho e do capital, segundo a visão neoliberal (atendimento público a demandas crescentes), o que significa dinamizar a produção do consentimento e disciplinamento da ação pública, fundamentalmente, pelo controle das contas e gastos públicos e pela garantia da

\footnotetext{
${ }^{8}$ Essa definição resulta fundamentalmente de definições do World Bank (1989; 1992).
} 
propriedade privada nos limites de uma governabilidade liberal9. Ou seja, fora das áreas críticas da Seguridade Social, na formação de consensos mínimos ${ }^{10}$, e da desregulação do Estado sobre o empreendimento privado.

Segundo essa perspectiva, a mobilização dos agentes sociais visa dar sustentação ao governo e apoia-se na prevalência dos valores morais e liberais de "bom governo" e disciplinamento de condutas. Em relação ao regime de acumulação, estimulam-se parcerias do governo com grandes agentes e corporações do mercado, sustentadas na garantia do marco legal de acesso à propriedade e, também, em parcerias com a esfera microssocial de agenciamento de programas públicos de ativação pelo trabalho, ou pelo empreendedorismo e o protagonismo das famílias no controle da reprodução, seguindo o cumprimento de contrapartidas dos programas sociais que implica num disciplinamento dos governos.

\section{B - Governança, como mediação entre estado e sociedade civil}

Nesse caso, a noção expressa um tipo de constitucionalidade do Estado "para fora", ou seja, sua externalização e abertura dos governos à sociedade civil, que não se restringe à burocracia dos governos ou do Estado. Os governos buscam incorporar a historicidade da sociedade civil, propiciando maior legitimidade e legalidade às ações públicas. Essa abertura não significa atribuir poderes constituintes às camadas populares (o que poderia afetar a reconstrução do Estado), mas visa gerar condições de legitimidade para que o Estado e os governos não entrem em colapso. Busca reduzir a distância entre a institucionalidade existente e a historicidade real da sociedade civil, produzindo legitimidade para os governos e evitando impasses para a ação do Estado e/ou frustrações para a sociedade civil. Essa noção de governança como arranjos no espaço público se aproxima das formulações de Ivo (1997; 1998) e McCartey; Halfani; Rodriguez (1998, p. 95-99).

Salazar (1998, p. 179) reconhece a importância da noção de governança como instância mediadora, mas considera essa perspectiva ainda muito próxima à tese da governabilidade e mais associada às dinâmicas institucionais do Estado. Prioriza, então, a

\footnotetext{
9 Para Salazar (1998, p. 176), no primeiro tipo de governança, associado aos ajustes, a participação social é admitida nos limites da estabilidade do sistema político, podendo criar um polo alternativo de um poder cidadão, baseado no poder social participativo.

${ }^{10}$ Ver capítulo II em (IVO. 2001).
} 
matriz societal do poder, resultantes das formas efetivas pelas quais a sociedade e a economia se organizam e interagem conflitivamente. Ou seja, considera como ponto de partida o "estado da sociedade" e não uma "sociedade para o Estado". Essa perspectiva leva em conta a sociabilidade real dos sujeitos em suas experiências vivenciadas com o mercado e as instituições, que condicionam o alcance dos resultados das decisões políticas e públicas.

Essa compreensão supõe a valorização de formas e valores específicos desses agentes sociais nas suas relações reais e efetivas com as instituições. Considera a capacidade dessas organizações e os resultados dessas ações compartilhadas, do ponto de vista de suas condições reais para encaminhar processos de integração desses sujeitos à economia e ao mercado, no usufruto dos bens públicos como direitos da cidadania, tendo por horizonte os princípios de equidade, segurança e melhoria do bem-estar dos cidadãos. Essa visão de Salazar corresponde ao que eu chamo de "governança cidadã", como descrevo a seguir.

\section{C - Governança cidadã, a contra-hegemonia do poder social}

A governança cidadã baseia-se na sociabilidade das camadas populares na vivência institucional das políticas, incluindo iniciativas dos trabalhadores e os movimentos identitários e as organizações de resistência de povos originais e comunidades tradicionais em luta por direitos e contra a deterioração das condições de vida, preservação do trabalho e do meio ambiente, em processos de resistência e reprodução social, construindo socialmente um desenvolvimento alternativo e adequado aos seus usos socioculturais. Ao invés de preocupar-se com a modernização do Estado ou do mercado, essa modalidade de ação de governança toma por base a sociabilidade real das formas de organização de vida e trabalho das classes populares e a participação na vida institucional, no usufruto dos direitos da cidadania e na economia nos territórios.

Esses processos de governança cidadã implicam a afirmação e o reconhecimento de um saber e um poder enraizado em redes sociais existentes (formais e informais), em movimentos sociais e em mecanismos de justiça e regras de convivência legais e informais, submetendo as instâncias legais à contra hegemonia dos agentes sociais e comunidades 
territorializadas ${ }^{11}$ na tomada de decisões sobre aspectos da vida coletiva. Marques (2012, 2015) ressalta o papel analítico das redes nos padrões de inter-relação entre atores privados e públicos conectados por diversos vínculos (formais, institucionais, informais, ilegais) e construídos por diversas razões (intencionais, com outras intenções ou ao acaso).

Considerada a realidade desses processos, em artigos meus anteriores (IVO, 2001, 2002 e 2015) apontei para dificuldades de uso da noção de capital social ${ }^{12}$. Da perspectiva de James Coleman (1988, p. 98), a noção enfatiza o senso prático das redes sociais segundo a ação racional e o cálculo estratégico e funcional da ação, orientada para resultados e benefícios possíveis. Coleman considera uma variedade de entidades que compartilham aspectos das estruturas sociais que podem ser facilitadoras de certas ações dos atores (pessoas ou grupos). Além de distanciar-se da concepção bourdieusiana de recursos existentes no processo de conhecimento e reconhecimento mútuo, o capital social, quando assumido como virtudes intrínsecas ao âmbito microssocial local, pode reforçar o isolamento dos agentes, restrito a uma sociabilidade que não transpõe os circuitos restritos dessas redes sociais locais, ademais de poder reforçar o controle de máfias locais sobre a organização da vida e trabalho das classes populares.

Os movimentos sociais abriram-se em redes transnacionais de luta, ampliando, alternativamente, as arenas de negociação dos direitos civis e econômicos das minorias, em escalas cada vez mais amplas. Nesses casos, a noção de governança envolve os contra poderes, constituídos em contextos de lutas, e redes de resistências das classes populares ou atores em luta pela garantia dos direitos sociais, políticos e civis no usufruto dos bens públicos e naturais; e dos bens de consumo coletivos das cidades.

O uso da governança aplicada aos povos e nacionalidades autóctones fundamenta uma nova epistemologia crítica sobre a perspectiva estritamente econômica do desenvolvimento, reorientada pela noção de "buen vivir" [bem viver], que implica diálogo permanente e construtivo de saberes sobre formas integradoras do homem com a natureza (terra, água, ar e solo), distinta da noção de "bem-estar ocidental" (ACOSTA, 2012, p. 202).

${ }^{11}$ A noção comunidade refere-se a um grupo de pessoas que compartilham objetivos comuns, partilham uma mesma herança cultural e histórica e ocupam um território geograficamente definido.

${ }^{12}$ A noção de capital social, originalmente formulada por Pierre Bourdieu, diz respeito a um conjunto de recursos atuais e potenciais ligados à participação em redes duráveis de relações mais ou menos institucionalizadas de conhecimento e inter-reconhecimento mútuo. (ACCARDO; CORCUFF, 1986). 
Reconhecendo essas várias especificidades têm sido realizadas pesquisas empíricas qualitativas sobre processos de governança no desenvolvimento local, que observam a constituição das redes de sociabilidade reais, ou seja, as formas como os sujeitos estão integrados entre si, constroem e reconstroem as condições de reciprocidade e produção do trabalho na sua participação nos mercados, como formas de resistência e luta para a reprodução social da família, em interação com o meio ambiente nos projetos de desenvolvimento territorial e local.

Por outro lado, programas públicos de combate à pobreza destacam o papel da família e das redes familiares como base nas estratégias de sobrevivência e formação da renda e sua importância da perspectiva do desempenho escolar e cognitivo dos filhos. Esse é o caso, por exemplo, do protagonismo das mulheres no apoio e controle das contrapartidas dos benefícios dos programas de transferência de renda.

\section{Conclusões}

A noção de governança foi introduzida como um ponto de partida normativo da ação coletiva orientada para a produção de acordos, em contextos assimétricos e de crise do capital dos anos oitenta, mas a dinâmica dessa ação a constitui também como um ponto de chegada na formação de consensos parciais em contextos de lutas.

Ela emergiu no receituário neoliberal como solução para a crise do capitalismo na década de oitenta, mas contrapõe-se a esses dispositivos pela mobilização do poder dos atores sociais e políticos organizados, na produção de uma contra hegemonia com base em direitos da cidadania e vivência da política. A reversão desse processo, no entanto, depende da capacidade de organização e pressão dos agentes sociais em torno de demandas específicas, na produção da justiça social e ambiental, e na mobilização desses atores em escalas mais amplas.

Considerando a estrutura social profundamente desigual dos países latino americanos, a perspectiva de uma governança cidadã, como é proposto nesse artigo, ligada à participação cidadã, depende da capacidade, força e amplitude dos movimentos sociais organizados em demandas por direitos sociais e sobre territórios, segundo um sentido mais amplo de justiça social e redistributiva, que envolve mecanismos de distribuição, processos de reconhecimento e reparação dos direitos sociais e o acesso aos bens públicos. Assim, a 
eficácia dos sistemas de governança desloca-se do campo institucional e normativo do "bom governo" para incorporar a construção dos direitos políticos e civis da cidadania de diversos segmentos sobre os territórios e, dentre estes, o direito à cidade, considerando a transversalidade dos direitos civis com direitos políticos e socioculturais.

Os significados da noção de governança, no campo da pesquisa sociológica contemporânea, estimulam, portanto, um exercício crítico sobre a emergência de categorias de alcance médio, como mediadoras de conflitivos e repactuação de relações de poder, tanto na esfera pública nas cidades (Direito à cidade), como nos contextos de novas regulações territoriais (Direito aos territórios), em que se efetivam confrontos entre as intervenções de governos, empresas e a ordem societária preexistente. A análise de como essas relações de poder se reproduzem mostra que elas são[ $\left.\mathrm{U}_{1}\right]$ construções necessariamente históricas e, ao mesmo tempo, contingentes dos sujeitos críticos do conhecimento, nas sociedades capitalistas contemporâneas.

\section{Referências}

ACCARDO, A; CORCUFF, P. La Sociologie de Bourdieu, (textes choisis et commentés). 2. ed. Bordeaux-Fr: Editions Le Mascaret,1986.

ACOSTA, Alerto. O Buen vivir - uma oportunidade de imaginar um outro mundo. In: Um campeão visto de perto. Uma análise do modelo de desenvolvimento brasileiro. Rio de Janeiro: Heirich Böll Foundation, 2012. p. 198- 216. (Série Democracia, 16 jul. 2012).

CAVALCANTI, Ana Claudia R. A difusão da agenda urbana das agências multilaterais de desenvolvimento na cidade de Recife. 2008, 213 f. Tese (Doutorado) - Universidade Federal de Pernambuco, Programa de Pós-Graduação em Desenvolvimento Urbano, 2012.

COLEMAN, James. S. Social Capital in the Creation of Human Capital. American Journal of Sociology. v. 94, p. 95-120, 1988.

FOUCAULT, Michel. A governamentalidade. In: Michel FOUCAULT. Microfísica do poder. Rio de Janeiro: Graal, 1979. p.277-293.

HAAS, Peter. Introduction: Epistemic Communities and International Polity Coordination. International Organization, v. 46, n. 01, p. 01-35, 1992.

GRAMSCI, Antonio. Cadernos do Cárcere. 2. ed. Rio de Janeiro: Editora Civilização Brasileira, 1999. HYDEN, Goran; BRATTON, Michael (ed.) Governance and the Study of Politics. In: Goran Hyden e Michael Bratton (eds.) Governance and Politics in Africa. Boulder, Colorado: Lynne Rienner, 1992. 
IPEA. Estado, instituições e democracia: democracia. Brasília: Ipea, 2010. Liv. 9, v. 2.

IVO, Anete B. L. Uma racionalidade constrangida: uma experiência de governança urbana em Salvador. Caderno CRH, Salvador, n. 26/27, p.107-145, 1997.

IVO, Anete B. L. L'expérience de gouvernance urbaine à Salvador de Bahia. Les Annales de la Recherche Urbaine, Paris, no 8o-81, p. 55-63, déc. 1998.

IVO, Anete B. L. Metamorfoses da questão democrática. Governabilidade e pobreza. Buenos Aires: CLACSO; ASDI, 2001.

IVO, Anete B. L. Recomposição Política, Comunidade Cívica e Governança Urbana. Cadernos Metrópole, São Paulo: EDUC, v. 8, p. 9-38, 2002.

IVO, Anete B. L. A reconversão do social: dilemas da redistribuição no tratamento focalizado. São Paulo em Perspectiva, São Paulo, v. 18, n.2, p. 57-67, 2004.

IVO, Anete B. L. Viver por um fio: pobreza e política social. São Paulo: Annablume Editora, 2008.

IVO, Anete B. L. Agências multilaterais de desenvolvimento e comunidades epistêmicas. Cadernos do CEAS, n.235, p. 129-152, 2015.

IVO, Anete B. L. A noção de governança. Um novo regime de ação para o desenvolvimento sustentável e a produção das ciências sociais. In: Anete B. L. Ivo. (org.). A reinvenção do desenvolvimento: agências multilaterais e produção sociológica. Salvador: EDUFBA, 2016. p. 37104 .

LAUTIER, Bruno. O consenso sobre as políticas sociais na América Latina, negação da democracia? Caderno CRH, Salvador, v.23, n.59, p.353-368, maio-ago. 2010.

LOFCHIE, Michael F. Perestroika Without Glasnost: Reflections on Structural Adjustment. In: Beyong Autocracy in Africa. Work in Papers from the Inaugural Seminar of the Governance in Africa Programme, The Carter Center of Emory University. Atlanta, Georgia, February 17-18, 1989.

MARQUES, Eduardo. Redes sociais no Brasil. Belo Horizonte: Argumentum, 2012.

MARQUES, Eduardo. A metrópole de São Paulo no século XXI: espaços, heterogeneidades e desigualdades. São Paulo: Editora Unesp; CEM, 2015.

McCARNEY, Patricia; HALFANI, Mohamed; RODRIGUEZ, Alfredo. Hacia uma definición de 'governanza'. Proposiciones, Santiago do Chile, n. 28, p. 118-155, 1998.

MOORE, Mick. Introduction. IDS Bulletin. Institute of Development Studies, Brighton - UK, v. 24 n.1, p. 1-6, 1 jan., 1993.

OSMOND, Anick. La gouvernance: concept mou, politique ferme. Les Annales de La Recherche Urbaine, Paris, n. 8o-81, p. 19-26, déc. 1998.

RHODES, R. A. W. The New Governance: Governing Without the Government. Political Studies Association, United Kingdom, v.44, n. 4, p. 652-667, sep. 1996. 
SALAZAR, G. De la participación ciudadana: capital social constante y capital variable (explorando senderos transliberais). Proposiciones, Santiago Chile, n.28, p.156-183, 1998.

SIMIONATO, I. Razões para continuar utilizando a categoria sociedade civil. In: CANTOIA LUIZ, D. E. (org.). Sociedade civil e democracia: expressões contemporâneas. São Paulo: Veras Editora, 2010

WILLIAM, David; YOUNG, Tom. Governance, the World Bank and Liberal Theory. Political Studies, XLII, p. 84-100, 1994.

WORLD BANK. Sub-Saharan Africa. From Crisis to Sustainable Growth. Washington: World Bank, 1989.

WORLD BANK. Governance and Development. Washington: World Bank, 1992.

WORLD BANK. Governance: The World Bank's Experience. Washington: World Bank, 1994.

WORLD BANK. The State in a Changing World. World Development Report 1997. Oxford: Oxford University Press; Washington: World Bank, 1997.

\section{Dados da autora}

Anete B.L. Ivo

Doutora em Sociologia pela Universidade Federal de Pernambuco, mestre em Ciências Sociais pela Universidade Federal da Bahia (1975) e em Sociedades Latino Americanas pela Université de Paris III (1980). É professora no Programa de Programa de Pós-Graduação em Ciências Sociais (UFBA) e professora colaboradora do Programa de Pós-Graduação em Políticas Sociais e Cidadania (UCSAL). Foi titular da Cátedra Simon Bolivar da Université de Paris III e Fllow do Comparative Research Programme on Poverty (CROP), do International Social Science Council (2014 a 2018). E-mail: anetivo@hotmail.com Lattes Id http://lattes.cnpq.br/9638917902863360 